\title{
Incremental-Entity Personal Conceptions of Intelligence and Individualism-Collectivism in Italian Students
}

\author{
Annamaria Pepi ${ }^{1}$ \\ Marianna Alesi ${ }^{1}$ \\ Donatella Pecoraro \\ Luísa Faria ${ }^{2}$ \\ 1Dipartimento di Scienze Psicologiche, Pedagogiche e della Formazione, \\ Università di Palermo, v.le delle Scienze, Edificio 15, 90128 Palermo \\ Email: ape@unipa.it \\ ${ }^{2}$ Faculdade de Psicologia e de Ciências da Educação, Universidade do Porto, Portugal \\ Email: Ifaria@fpce.up.pt
}

\section{Doi:10.5901/mjss.2015.v6n1s1p160}

\section{Abstract}

This article examines the relationship between Incremental-Entity personal conceptions of intelligence and the cultural dimension of Individualism-Collectivism in Italian students attending high school. Four types of individualism and collectivism were investigated: 1) Vertical-Individualism, characterized by independent and different self; 2) Horizontal-Individualism, characterized by independent and similar self; 3) Vertical-Collectivism, characterized by interdependent and different self; and 4) Horizontal-Collectivism, characterized by interdependent and similar self. The sample includes 250 students,3th and 5th graders. A battery of tests including a Sociodemographic Questionnaire, the Italian version of the Scale of Personal Conceptions of Intelligence (Pepi, Faria, \& Alesi, 2007) and the Italian version of the Daily Life Situations Questionnaire (Ciochină \& Faria, 2006) were collectively administered during regular school hours. On the whole, results place the Italian students toward the pole of individualism with the representation of intelligence more oriented in entity terms. Moreover differences were found regarding the 4 contexts: School, Peer Group, Family and General Context. In conclusion, the research pointed out the close association between differences in personal beliefs about intelligence, such as the personal conceptions of intelligence, and the cultural dimension of individualism/collectivism.

Keywords: personal conceptions of intelligence, individualism, collectivism, cultural context.

\section{Introduction}

In recent years, there has been a renewed interest in the analysis of the cultural dimension of individualism-collectivism. It is becoming increasingly evident that different cultural prototypes influence the development of cognitive styles as well as motivational constructs such as self-concept, self-esteem, causal attributions and personal conceptions of intelligence (Oyserman\& Lee, 2008).

This study is in continuity with previous research (Pepi, Faria, \& Alesi, 2004, 2006, 2007, 2008, 2012) which examined the personal conceptions of intelligence and the cultural dimension of individualism-collectivism in Italian and Portuguese students attending high school and University contexts.

Implicit theories or personal conceptions of intelligence have proved to be very important, since they affect individual's cognitions, affects and behaviors by influencing the achievement goals, the causal attributions for success and failure, and the future expectations (Dweck, 1999; Furnham, 2001; Little \& Lopez, 1997).

Original research developed by Dweck and colleagues postulated two different conceptions about the nature of intelligence - the static/entity conception vs. the incremental one - which represent two self-systems (Dweck, 1999; Dweck \& Leggett, 1988; Faria, 1998, 1996).

Specifically, individuals holding the incremental conception perceive intelligence as a quality which can be improved through personal investment and effort.They also tend to adopt learning goals based on their desire to master new skills and increase their competence by adopting effective strategies and choosing challenging tasks. On the other hand, individuals with a static conception perceive intelligence as a gift with which the individual is endowed and cannot 
change no matter how hard he/she can work. So they tend to adopt performance goals to show their abilities and receive positive judgments from the evaluative contexts (Dweck, 1999; Erdley, Cain, Loomis, Dumas-Hines, \& Dweck, 1997).

A large body of literature have found correlations between school grades and personal conceptions of intelligence: on the whole, students who adopt an incremental conception tend to get higher grades than those with a static one (Faria, 1996; Pepi, Alesi, \& Faria, 2006; Stipek \& Gralinski, 1991).

Traditionally, cross-cultural studies of ability-related beliefs have long been focused on the analysis of the individualism-collectivism dichotomy (Harrington \& Liu, 2002; Heine, Kitayama, \& Lehman, 2001; Hofstede, 1980; Kagitçibaci, 1994). The individualism focuses on the individual as the unit of analysis in a society by emphasizing the perception of the uniqueness of personal qualities. Consequently, the self develops independently from the group, with particular accent on idiocentrism, self-efficiency, autonomy, competition and personal goals aimed at pursuing selfrealization and success (Carver, Lawrence, \& Scheier, 1996; Triandis, McCusker, \& Hui, 1990). On the contrary, the collectivism focuses on the group as the unit of analysis in a society, maximizes the personal engagement and commitment as dimensions defined by one's own group of reference. Crucial aspects are allocentrism, obedience, and conformity, with special attention given to the family as the most important in-group (Georgiou, 1995).

Nevertheless, Markus and Kitayama (1991) argued that individualism and collectivism may be two independent dimensions. Subsequent models split each of the facets into vertical and horizontal sub-dimensions (Singelis, Triandis, Bhawuk, \& Gelfand, 1995) by treating individualism and collectivism as extremes of a single dimension. So, four types of Individualism/Collectivism were identified: 1) Vertical-Individualism characterized by independent and different self; 2) Horizontal-Individualism characterized by independent and similar self; 3) Vertical-Collectivism characterized by interdependent and different self; and 4) Horizontal-Collectivism characterized by interdependent and similar self.

So, Vertical-Individualists focus on their own thing and wish for to be the best, Horizontal-Individualists are willing to do "their own thing", Vertical-Collectivists tend to be subordinate to the authorities of the group and HorizontalCollectivists melt in the group and lose their selves (Triandis, 2001)

The correlates of these differences in individualism/collectivism foster distinct belief systems about the meaning of the terms "ability" and "effort" and influence personal conceptions of intelligence. Specifically, individualistic people tend to focus the conception of "intelligence" on one's motivational attributes such as effort, interest, curiosity; collectivistic people, on the contrary, perceive the intelligence in terms of pragmatic and social factors, "... getting by in society, not committing big mistakes, appearing intelligent in life"(Ciochină \& Faria, 2006, p. 1024).

In this theoretical context, Italy is classified as an individualistic culture featured by the dominance of individual interests, freedom of the press, and the search for personal self-realization as the main personal goals (Faria, Pepi, \& Alesi, 2004; Pepi, Faria, \& Alesi, 2004).

Given these theoretical premises, this study aims to investigate the relationship between personal conceptions of intelligence and the four dimensions of individualism/collectivism (Vertical-Individualism, Horizontal-Individualism, Vertical-Collectivism and Horizontal-Collectivism) in a sample of Italian adolescents attending high school.

\section{Method}

\subsection{Participants}

The sample consisted of 250 Italian students with an average age of 17.73 years (SD=1.264) attending their 3th or 5th year of high school (humanistic, scientific, technical and psycho-pedagogical schools). In particular, the first group consisted of 129 students, with an average chronological age of 16.64 years $(S D=.682)$ and the second consisted of 121 students with an average chronological age of 18.64 years $(S D=.797)$. With regard to gender, there were more females than males (56.7\% females and $43.3 \%$ males) and medium socioeconomic status (6.4\% high, $8 \%$ medium-high, $55.2 \%$ medium and $30.4 \%$ medium-low) was predominant (see Table 1 ).

Table 1 - Sample distribution by school grade, gender, socioeconomic status and scholastic emphasis.

\begin{tabular}{c|cccccccccccccccc}
\hline & \multicolumn{3}{|c}{ School grade } & \multicolumn{3}{c}{ Gender } & \multicolumn{4}{c}{ *Socioeconomic status } & \multicolumn{4}{c}{${ }^{*}$ Scholastic emphasis } \\
\hline & $3^{\text {th }}$ & $5^{\text {th }}$ & $\mathrm{T}$ & $\mathrm{F}$ & $\mathrm{M}$ & $\mathrm{T}$ & $\mathrm{H}$ & $\mathrm{MH}$ & $\mathrm{M}$ & $\mathrm{ML}$ & $\mathrm{T}$ & $\mathrm{H}$ & $\mathrm{S}$ & $\mathrm{T}$ & $\mathrm{P}$ & $\mathrm{T}$ \\
\hline $\mathrm{N}$ & 129 & 121 & 250 & 141 & 109 & 250 & 16 & 20 & 138 & 76 & 250 & 82 & 25 & 78 & 65 & 250 \\
$\%$ & 51.6 & 48.4 & 100 & 56.4 & 43.6 & 100 & 6.4 & 8 & 55.2 & 30.4 & 100 & 26 & 10 & 31.2 & 26 & 100 \\
\hline
\end{tabular}

Legend: *Socioeconomic status $\mathrm{H}=$ high; $M H=$ =medium-high; $M=$ medium; $M L=$ medium-low; **Scholastic emphasis $H=$ humanistic; $S=$ scientific; $T$ = technical; $P=$ psycho-pedagogical 


\subsection{Instrument and Procedure}

A cross-sectional research design was adopted.

Students were administered a battery of tests composed by a Sociodemographic Questionnaire, the Italian version of the Scale of Personal Conceptions of Intelligence (Pepi, Faria, \& Alesi, 2007) and the Daily Life Situations Questionnaire (Ciochină \& Faria, 2006).

More specifically, the Sociodemographic Questionnaire was used to collect data related to gender, age, level of education and school emphasis (humanistic, scientific, technical and psycho-pedagogical schools) and to identify the socioeconomic status - SES- (high, medium-high, medium and medium-low) through parameters such as the educational level and the profession of students' parents.

The Italian version of the Scale of Personal Conceptions of Intelligence (ECPI, Faria \& Fontaine,1997), was used to assess personal conceptions of intelligence (Pepi, Faria, \& Alesi, 2007); it includes 26 items, 11 items for the incremental (example: "Effort enables me to become more intelligent") and 15 items for the static conception (example: "I have a certain amount of intelligence and I can't do much to change it'), scored from 1 to 6 , a higher score indicating more dynamic or less static conceptions of intelligence. The results of factor analyses highlighted the existence of two distinct factors, a static and a dynamic one, which together explained $40 \%$ of the total variance observed. The internal consistency of the scales yielded alpha coefficients between .72 and .80. The Daily Life Situations Questionnaire - DLSQ (Ciochină \& Faria, 2006) measures four types of individualism-collectivism (IND/COL):

- Vertical-Individualism (independent and different self) - V.I.

- Horizontal-Individualism (independent and similar self) - H.I.

- Vertical-Collectivism (interdependent and different self) - V.C.

- Horizontal-Collectivism (interdependent and similar self) - H.C.

It consists of 24 items representing 24 life scenarios which describe a variety of social situations in which different individualistic and collectivistic attitudes and behaviors may arise.

Social situations are divided into four contexts that constitute 4 subtests (School; Peer Group; Family and General).

Example of one item of the subtest School Context:

2. You believe that a successful colleague / classmates is:

a) The person who always gets the best grades.

b) The person who loves to learn and get good results that make him / her proud with himself /herself.

c) The person who respects teachers and their authority.

d) The person who has good relations with others.

Example of one item of the subtest Peer Group Context:

15. Which of the following activities do you prefer:

a) Thinking to myself.

b) Cooperate with others.

c) Doing things for the sake of others.

d) Being in competition with others and win.

Example of one item of the subtest Family Context:

11. What is the most important quality that your colleague needs to be defined as intelligent:

a) To share its knowledge with other colleagues.

b) To win school competitions (such as the Olympics, sports competitions).

c) To be a good learner in order to get a successful job.

d) To learn from people more expert than yourself.

Example of one item of the subtest General Context:

18. Imagine that you are asked to describe yourself in one word. Please order the following words according to the degree in which you describe:

a) Unique.

b) Competitive.

c) Cooperative.

d) Responsible.

Each situation (life situation) has four response alternatives which need to be ordered by the participants from 1 to 4 , according to their order of preference - 1 is the response which most illustrates their way of thinking and behaving and 4 is the response which characterizes them the least. These four response alternatives illustrate the four types of 
IND/COL mentioned above: VI, HI, VC and HC.

The administration was collective and took about 20 minutes.

This methodology was chosen because of the nature of the investigated construct. The theoretical framework (Singelis, Triandis, Bhawuk, \& Gelfand, 1995) of four types of Individualism/Collectivism was adopted considering the vertical and horizontal sub-dimensions of individualism and collectivism.

\subsection{Results}

Table 2 shows the absolute frequency distribution and the percentage of students holding the static/entity or the incremental personal conception of intelligence.

In particular, with regard to the Italian version of the Scale of Personal Conceptions of Intelligence, $92.4 \%(231)$ of the students held conceptions of intelligence more static oriented, while only $7.6 \%$ (19) of the students held a dynamic conception of intelligence.

Moreover, the percentages of choice of the Daily Life Situations Questionnaire were calculated as a function of the Scale of Personal Conceptions of Intelligence (see tables 2, 3, 4 and 5), as follows:

- School Context: Significant differences between entity and incremental students were found in the following items: item 2 in Vertical Individualism answers $\left(X^{2}(3)=7.938\right.$; $\left.p<.05\right)$; item 5 in Vertical Individualism answers $\left(X^{2}(3)=10.580 ; p<.05\right)$ item 16 in Horizontal Collectivism answers $\left(X^{2}(3)=18.507 ; p<.05\right)$; and item 20 in Horizontal Individualism answers $\left(X^{2}(3)=8.233 ; p<.05\right)$.

The students holding a static conception of intelligence showed the highest percentages of HorizontalIndividualism in the items 5, 2, 20 and 9. Specifically, the item $5(72.4 \%)$ evaluated the school goals of the subject; the item $2(64.6 \%)$ assessed the features of successful schoolmate; the item $20(33 \%)$ evaluated the behavior of the subject following the parents' opinion about their friends and the item 9 (30.9\%) assessed the meaning of success for the subject.

On the contrary, students holding a dynamic personal conception of intelligence showed the greatest HorizontalCollectivism in their choices to the items 16, 19, 9 and 20.Specifically, the item $16(72.2 \%)$ assessed the perception of the subject towards the ideal teacher; the item 19 (47.1\%) assessed the meaning of friendship (see Table 2).

Table 2. Percentages of answers for the subtest "School Context" of Daily Life Situations Questionnaire according to the personal conceptions of intelligence.

\begin{tabular}{|c|c|c|c|c|c|c|c|c|}
\hline \multicolumn{5}{|c|}{ Static } & \multicolumn{4}{|c|}{ Incremental } \\
\hline Items & V.I & H.I & V.C & H.C & V.I & H.I & V.C & $\mathrm{H} . \mathrm{C}$ \\
\hline 2 & $19.0 \%$ & $64.6 \%$ & $3.6 \%$ & $14.5 \%$ & $38.9 \%$ & $66.7 \%$ & $29.4 \%$ & $17.6 \%$ \\
\hline 5 & $5.8 \%$ & $72.4 \%$ & $19.9 \%$ & $2.7 \%$ & $17.6 \%$ & $52.9 \%$ & $36.8 \%$ & $23.5 \%$ \\
\hline 9 & $13.0 \%$ & $30.9 \%$ & $28.6 \%$ & $28.8 \%$ & $11.8 \%$ & $17.6 \%$ & $33.3 \%$ & $41.2 \%$ \\
\hline 16 & $17.1 \%$ & $9.5 \%$ & $44.8 \%$ & $29.8 \%$ & $41.2 \%$ & $5.9 \%$ & $23.5 \%$ & $72.2 \%$ \\
\hline 19 & $36.4 \%$ & $4.1 \%$ & $15.2 \%$ & $45.7 \%$ & $22.2 \%$ & $5.9 \%$ & $29.4 \%$ & $47.1 \%$ \\
\hline 20 & $6.3 \%$ & $33.0 \%$ & $7.2 \%$ & $54.2 \%$ & $53.3 \%$ & $46.7 \%$ & $25.0 \%$ & $37.5 \%$ \\
\hline Tot. & $97.6 \%$ & $214.5 \%$ & $119.3 \%$ & $175.7 \%$ & $185 \%$ & $195.7 \%$ & $177.4 \%$ & $239.1 \%$ \\
\hline
\end{tabular}

Legend: V.I Vertical-Individualism; H.I Horizontal-Individualism; V.C Vertical-Collectivism; H.C Horizontal-Collectivism.

- Peer Group Context: Significant differences between entity and incremental students were found in the following items: item 3 in Horizontal Individualism answers $\left(X^{2}(3)=17.015 ; p<.05\right)$; item 12 in Horizontal Individualism answers $\left(X^{2}(3)=12.700 ; p<.05\right)$ and Horizontal Collectivism answers $\left(X^{2}(3)=9.653 ; p<.05\right)$; item 14 in Horizontal Collectivism answers $\left(X^{2}(3)=10.542 ; p<.05\right)$.

Both the students holding static and dynamic conceptions of intelligence demonstrated the greatest HorizontalCollectivism in their choices,more clearly the items 14, 3, 12 and 21 showed the highest percentages of choice in the group of static students. Specifically, the item 14 (76.7\%) assessed the loving relationships; the item $3(59.2 \%)$ evaluated the choice and the decision to buy a gift with friends; the item 12 (54.7\%) assessed the favorite activities from the subject and the item $21(41.3 \%)$ assessed the behavior of altruism / egoism of the subject in relation to schoolmates.

Instead, in the group of dynamic students the items 14 (70.6\%), 3 (52.9\%), 21 (38.9\%) and 24 (33.3\%) showed the highest percentages of choice.

Specifically, the item 24 assessed the subject's choice to spend the holidays with their parents, (see Table 3). 
Table 3. Percentages of answers for the subtest "Peer Group Context" of Daily Life Situations Questionnaire

\begin{tabular}{c|c|c|c|c|c|c|c|c|}
\hline \multicolumn{9}{c}{ Static } \\
\hline Items & V.I & H.I & V.C & H.C & V.I & H.I & V.C & H.C \\
\hline 3 & $8.9 \%$ & $6.2 \%$ & $26.8 \%$ & $59.2 \%$ & $11.8 \%$ & $5.9 \%$ & $36.8 \%$ & $52.9 \%$ \\
\hline 12 & $5.8 \%$ & $11.6 \%$ & $29.0 \%$ & $54.7 \%$ & $18.8 \%$ & $37.5 \%$ & $23.5 \%$ & $29.4 \%$ \\
\hline 14 & $5.9 \%$ & $16.3 \%$ & $1.8 \%$ & $76.7 \%$ & $12.5 \%$ & $27.8 \%$ & $82.4 \%$ & $70.6 \%$ \\
\hline 15 & $22.2 \%$ & $70.8 \%$ & $3.6 \%$ & $4.1 \%$ & $22.2 \%$ & $72.2 \%$ & $5.9 \%$ & $5.9 \%$ \\
\hline 21 & $8.1 \%$ & $4.9 \%$ & $46.9 \%$ & $41.3 \%$ & $11.8 \%$ & $11.8 \%$ & $44.4 \%$ & $38.9 \%$ \\
\hline 24 & $13.7 \%$ & $35.6 \%$ & $35.4 \%$ & $16.4 \%$ & $38.9 \%$ & $29.4 \%$ & $5.9 \%$ & $33.3 \%$ \\
\hline Tot. & $64.6 \%$ & $145.4 \%$ & $143.5 \%$ & $252.4 \%$ & $116.0 \%$ & $184.6 \%$ & $198.9 \%$ & $231.0 \%$ \\
\hline
\end{tabular}

Legend: V.I Vertical-Individualism; H.I Horizontal-Individualism; V.C Vertical-Collectivism; H.C Horizontal-Collectivism.

- Family Context: Significant differences between entity and incremental students were found in the following items: item 7 in Horizontal Individualism answers $\left(X^{2}(3)=32.753 ; p<.05\right)$ and Vertical Collectivism answers $\left(x^{2}(3)=9.855 ; p<.05\right)$;item 13 in Horizontal Individualism answers $\left(X^{2}(3)=11.884 ; p<.05\right)$, Horizontal Collectivism answers $\left(X^{2}(3)=9.827 ; p<.05\right)$ and Vertical Collectivism $\left(X^{2}(3)=10.664 ; p<.05\right) ;$ item 17 in Vertical Individualism answers $\left(X^{2}(3)=16.536 ; p<.05\right)$ and Horizontal Individualism answers $\left(X^{2}(3)=12.833\right.$; $p<.05)$.

The students holding a static conception of intelligence showed preferentially Horizontal-Individualism choices; examples of this are the items 7,23, 11 and 17.

Specifically, the item $7(86.5 \%)$ assessed the factors which influence the choice of a course of education; the item $23(66.4 \%)$ assessed the behavior of the subject faced with the choice between two different situations; the item 11(42.2\%) assessed indirectly the qualities to be considered intelligent, and the item 17 (36.2\%) assessed how the subject would act to be accepted by the members of a new group.

Instead, students oriented in terms of dynamic conceptions of intelligence showed the greatest Vertical Individualism in their choices for the items 13 (66.7\%), 1 (61.1\%), 17 (33.3\%) and 7 (29.4\%).

Specifically, the item 13 assessed the behavior towards friends, and the item 1 assessed indirectly if the subject accepts the parents advice (see Table 4).

Table 4. Percentages of answers to the items of the subtest "Family Context" of Daily Life Situations Questionnaire

\begin{tabular}{|c|c|c|c|c|c|c|c|c|}
\hline \multicolumn{1}{c}{ Static } & \multicolumn{4}{c}{ Incremental } \\
\hline Item & V.I & H.I & V.C & H.C & V.I & H.I & V.C & H.C \\
\hline 1 & $28.9 \%$ & $16.7 \%$ & $27.6 \%$ & $27.3 \%$ & $61.1 \%$ & $5.9 \%$ & $16.7 \%$ & $23.5 \%$ \\
\hline 7 & $10.6 \%$ & $86.5 \%$ & $1.3 \%$ & $2.2 \%$ & $29.4 \%$ & $50.0 \%$ & $11.8 \%$ & $11.8 \%$ \\
\hline 11 & $2.7 \%$ & $42.2 \%$ & $32.0 \%$ & $23.8 \%$ & $16.7 \%$ & $44.4 \%$ & $23.5 \%$ & $23.5 \%$ \\
\hline 13 & $52.9 \%$ & $6.8 \%$ & $13.9 \%$ & $27.5 \%$ & $66.7 \%$ & $27.8 \%$ & $11.8 \%$ & $17.6 \%$ \\
\hline 17 & $8.9 \%$ & $36.2 \%$ & $41.8 \%$ & $14.3 \%$ & $33.3 \%$ & $29.4 \%$ & $33.3 \%$ & $11.8 \%$ \\
\hline 23 & $5.0 \%$ & $66.4 \%$ & $8.1 \%$ & $21.6 \%$ & $11.8 \%$ & $57.9 \%$ & $23.5 \%$ & $11.8 \%$ \\
\hline Tot. & $109.0 \%$ & $254.8 \%$ & $124.7 \%$ & $116.7 \%$ & $219.0 \%$ & $215.4 \%$ & $120.6 \%$ & $100.0 \%$ \\
\hline
\end{tabular}

Legend:V.I Vertical-Individualism; H.I Horizontal-Individualism; V.CVertical-Collectivism; H.C Horizontal-Collectivism.

- General Context: Significant differences between entity and incremental students were found in the following items: item 4 in Vertical Collectivism answers $\left(X^{2}(3)=12.906 ; p<.05\right)$; item 18 in Vertical Individualism answers $\left(x^{2}(3)=13.305 ; p<.05\right)$ and Horizontal Collectivism answers $\left(X^{2}(3)=14.193 ; p<.05\right)$; item 22 in Horizontal Individualism answers $\left(X^{2}(3)=12.978 ; p<.05\right)$, Vertical Individualism answers $\left(X^{2}(3)=19.656\right.$; $p<$ .05),Vertical Collectivism answers $\left(x^{2}(3)=10.362 ; p<.05\right)$ and Horizontal Collectivism answers $\left(x^{2}(3)=\right.$ 13.076; $p<.05)$.

Both the students holding static and dynamic conceptions of intelligence showed the greatest HorizontalIndividualism in their choices.

More clearly, the items 22 (70.7\%), 4 (53.3\%), 6 (36.5\%) and 18 (27.6\%) received the highest percentages for the static students.

Specifically, the item 22 assessed what the subject expects from a future profession; the item 4 assessed the behavior of the subject in leisure activities; the item 6 assessed the confidential relationship between the subject and the 
parents, and the item 18 assessed the self-image.

Instead, the items 22 (50.0\%), 4 (35.3\%), 18 (33.3\%), 6 (29.4\%) and 10 (29.4\%) showed the highest percentages for the dynamic students.

Specifically, the item 10 assessed the behavior of the subject in front of financial straits, (see Table 5).

Table 5. Percentages of answers for the subtest "General Context" of Daily Life Situations Questionnaire

\begin{tabular}{|c|c|c|c|c|c|c|c|c|}
\hline \multicolumn{9}{c|}{ Static } \\
\hline Items & V.I & H.I & V.C & H.C & V.I & H.I & V.C & H.C \\
\hline 4 & $7.1 \%$ & $53.3 \%$ & $3.6 \%$ & $36.6 \%$ & $25.0 \%$ & $35.3 \%$ & $29.4 \%$ & $41.2 \%$ \\
\hline 6 & $35.9 \%$ & $36.5 \%$ & $15.8 \%$ & $13.1 \%$ & $47.4 \%$ & $29.4 \%$ & $17.6 \%$ & $11.8 \%$ \\
\hline 8 & $3.1 \%$ & $18.1 \%$ & $22.6 \%$ & $57.5 \%$ & $5.9 \%$ & $16.7 \%$ & $11.8 \%$ & $72.2 \%$ \\
\hline 10 & $10.8 \%$ & $18.8 \%$ & $14.3 \%$ & $57.3 \%$ & $17.6 \%$ & $29.4 \%$ & $16.7 \%$ & $44.4 \%$ \\
\hline 18 & $8.0 \%$ & $27.6 \%$ & $53.1 \%$ & $11.9 \%$ & $11.1 \%$ & $33.3 \%$ & $42.1 \%$ & $16.7 \%$ \\
\hline 22 & $7.2 \%$ & $70.7 \%$ & $5.0 \%$ & $17.9 \%$ & $29.4 \%$ & $50.0 \%$ & $17.6 \%$ & $5.9 \%$ \\
\hline Tot. & $72.1 \%$ & $225.0 \%$ & $114.4 \%$ & $194.3 \%$ & $136.4 \%$ & $194.1 \%$ & $135.2 \%$ & $192.2 \%$ \\
\hline
\end{tabular}

Legend: V.I Vertical-Individualism; H.I Horizontal-Individualism; V.C Vertical-Collectivism; H.C Horizontal-Collectivism.

\section{Discussion and Conclusion}

On the whole, the results place the Italian students toward the pole of horizontal individualism with the representation of intelligence more oriented in static terms.

These results confirm previous research which found higher levels of entity conceptions of intelligence in Italian samples (Faria, Alesi, \& Pepi, 2004; Pepi, Faria, \& Alesi, 2006; Pepi, Faria, Alesi, \& Ciochină, 2012). Entity personal conceptions of intelligence direct people towards performance goals aimed at demonstrating others personal skills. Consequently, individuals with these conceptions and goals are concerned to appear intelligent and capable and tend to perceive every task as a test-bank of their intelligence. This system of beliefs fits well to the cultural values of individualism related to the degree to which people prefer to perform as unique individual rather than as member of groups.In general, each individualist sees himself as an independent and stand-alone respect to the community or group to which he belongs, and is committed to building and maintaining relationships with others only if he can get the real benefits. The typical features of the individualist are the security in itself, the competitiveness, putting personal interests before to those of the community/group (Hofstede, 1980). In individualistic societies people are educated from childhood to pursue their personal goals and interests, and aims to form their personalities as separate and independent from those of their families (Pepi, Faria, \& Alesi, 2006).

Moreover, it is plausible to find developmental and social explanations of results. This perception of stability and entity is consistent with the typical worries of adolescents when leaving high school. More specifically, at this age, students face difficulties in entering university or the job market, they feel the competitive pressure and anxiety of unknown experiences and events. All these factors are reinforced by the general sense of pessimism and country economic difficulties and, in turn, encourage the more static perception of personal abilities. So, the beliefs about one's own ability need to be interpreted with reference to a wider macro-context including the economic and political systems, as well as social aspects which involve a complex interaction between the ecological and geographic features. In Italy the unemployment rate, dated August 2014, is about $12.8 \%$. This is cause of worries and pessimism for Italian adolescents and youth. Moreover it could explain the high discrepancy between entity (92.4\%) and incremental (7.6\%) theorists in our sample.

Moreover, when we analyzed separately the four social contexts (school, peer group, family and general), we found interesting differences concerning the four types of individualism-collectivism: Vertical-Individualism (independent and different self), Horizontal-Individualism (independent and similar self), Vertical-Collectivism (interdependent and different self) and Horizontal-Collectivism (interdependent and similar self).

Students holding a static personal conception of intelligence demonstrated an increased Horizontal-Individualism related to School, Family and General contexts. This is characterized by the principle of equality between individuals; in fact, these people tend to feel unique and stand out from the group, but they are not very interested in changing their status.

Only in the Peer Group Context, static students demonstrated a greater Horizontal-Collectivism which tends to identify with the group; these subjects place great emphasis to interdependence, sociability and common goals. Also 
students oriented in terms of dynamic conceptions of intelligence showed the greatest Horizontal-Collectivism in the School and in the Peer Group contexts. We can conjecture that this result is mainly consistent with characteristics of peers groups such as socialization opportunities, cooperating with others, respecting rules, experiencing personal achievement by obtaining the encouragement of peers (Battaglia, Alesi, Inguglia, Roccella, Caramazza, Bellafiore \& Palma, 2013). Similarly, every collectivist sees himself as necessarily included in the group. The typical features of a collectivist are respect for others and cooperation. The collectivist approach focuses on the primary interests of the group or community of which the individual is a part.

In conclusion, the cultural dimension of individualism/collectivism is closely associated to motivational profiles intended as individual differences with a broad cultural background related to different socio-cultural factors such as attitudes, beliefs, personal experiences, family of origin, socioeconomic level, vulnerability to stereotypes. Indeed, differences in individualism and collectivism are correlated with systematic differences in content of personality constructs such as personal conceptions of intelligence, self-concept, nature of relationships with others and cognitive style (Oyserman, Coon, \& Kemmelmeier, 2002; Oyserman \& Lee, 2008; Triandis, 2001). Nevertheless, it is important to emphasize that each culture can't be characterized as either individualistic or collectivistic. Individualism and collectivism are not simply opposite sides of a single dimension, but are often inter-related through orthogonal aspects. So the system vertical-horizontal versus individualism-collectivism well embodies this multidimensional perspective aimed at identifying many varieties of individualism and collectivism.

In conclusion, future research is needed building on this study. It is important to acknowledge the shortcomings of this study. First, it is important to emphasize that this is a pilot study. Our data refer to a limited sample recruited only in one country characterized as individualistic. This is a factor which may limit the generalizability of our research. Additional research should extend the sample with subjects of other countries.

\section{Acknowledgement}

This study was carried out with funds of the University of Palermo/ltaly (Bando CoRI, 2011) and the Faculty of Psychology and Educational Sciences - University of Porto/Portugal.

\section{References}

Battaglia, G., Alesi, M., Inguglia, M., Roccella, M., Caramazza, G., Bellafiore, M.,\& Palma, A. (2013). Soccer practice as an add-on treatment in the management of individuals with a diagnosis of schizophrenia.Neuropsychiatric Disease and Treatment, 9, 595603.

Carver, C. S., Lawrence, J. W., \& Scheir, M. F. (1996).A control-process perspective on the origins of affect. In L. L. Martin, \& A. Tesser (Eds.), Striving and feeling: interactions among goals, affect and self-regulation (pp. 11-52). Matthew, N.J: Lawrence Erlbaum Association.

Ciochină, L., \& Faria, L. (2006). Concepçõ espessoais de inteligência de estudantes portugueses e romenos: Estudo preliminar de análise factorial confirmatória. Psychologica, 41, 171-191.

Dweck, C. S. (1999). Self-theories: Their role in motivation, personality, and development. Trad. it. A. Moè (Ed.), (2000), Teorie del sé. Intelligenza, motivazione, personalità e sviluppo. Trento: Erickson.

Dweck, C. S., \& Leggett, E. L. (1988).A social-cognitive approach to motivation and personality.Psychological Review, $95(2), 256$.

Erdley, C. S., Cain, K., Loomis, C., Dumas-Hines, F., \& Dweck, C. S. (1997).The relations among children's social goals, implicit personality theories and response to social failure.Developmental Psychology, 33, 263-272.

Faria, L. (1996). Personal conceptions of intelligence: A developmental study in Portugal. PsychologicalReports, 79, $1299-1305$.

Faria, L. (1998). Desenvolvimento diferencial das concepções pessoais de inteligência durante a adolescência. Lisboa: Fundação Calouste Gulbenkian e JuntacNacional de Investigação Científica e Tecnológica.

Faria, L., \& Fontaine, A. M. (1997). Adolescents' personal conceptions of intelligence: The development of a new scale and some exploratory evidence. European Journal of Psychology of Education, XII, (1), 51-62.

Faria, L., Pepi, A., \&Alesi, M. (2004). Concepçõespessoais de inteligência e auto-estima: Que diferenças entre estudantes portugueses e italianos?. Análise Psicológica,22(4), 747-764.

Furnham, A. (2001). Self-estimates of intelligence: Culture and gender difference in self and other estimates of both general $(\mathrm{g})$ and multiple intelligences.Personality and Individual Differences, 31, 1381-1405.

Georgiou, S. (1995).Family dynamics and school achievement in Cyprus. Journal of Child Psychology and Psychiatry, 56(6), $977-991$.

Harrington, L., \& Liu, J. H. (2002).Self-enhancement and attitudes toward high achievers.Journal of Cross-Cultural Psychology, 33(1), 37-55.

Heine, S. J., Kitayama, S., \& Lehman, D. R. (2001).Cultural differences in self-evaluation.Journal of Cross-Cultural Psychology, 32(4), 434-443.

Hofstede, G. (1980). Culture's consequences.Beverllly Hills, CA: Sage. 
Kagitçibasi, Ç. (1994). A critical appraisal of individualism and collectivism: toward a new formulation. In U. Kim, H. C. Triandis, Ç. Kagitçibasi, S. S. Choi, \& G. Yoon (Eds.), Individualism and collectivism. Theory, method and applications (pp. 52-66). Thousand Oaks, CA: Sage Publications Inc.

Little, T. D., \& Lopez, D. F. (1997).Regularities in the development of children's causality beliefs about school performance across six sociocultural contexts.Developmental Psychology, 33, 165-175.

Markus, H. R., \&Kitayama, S. (1991). Culture and the self: Implications for cognition, emotion and motivation. Psychological Review, 98(2), 224-253.

Oyserman, D., Coon, H.,\& Kemmelmeier, M. (2002) Rethinking individualism and collectivism: Evaluation of theoretical assumptions and meta-analyses. Psychological Bulletin, 128, 3-72.

Oyserman, D., \& Lee, S. W. (2008). Does culture influence what and how we think? Effects of priming individualism and collectivism. Psychological Bulletin, 134(2), 311-342.

Pepi, A., Faria, L., \& Alesi, M. (2004). La rappresentazione dell'intelligenza e l'autostima: Uno studio cross-culturale. Ciclo Evolutivo e Disabilità, VII(1), 31-48.

Pepi, A., Faria, L., \& Alesi, M. (2006). Personal conceptions of intelligence, self-esteem and school achievement in Italian and Portuguese students. Adolescence, 41, 615-631.

Pepi, A., Faria, L., \& Alesi, M. (2007). La Scala delle Concezioni Personali dell'Intelligenza: Un confronto tra le caratteristiche psicometriche della versione portoghese e di quella italiana. Bollettino di Psicologia Applicata, 251, 33-44.

Pepi, A., Faria, L., Alesi, M., \&Ciochină, L. (2012). The Scale of Personal Conceptions of Intelligence: A comparison of the Italian, Portuguese, and Romanian versions. Life Span and Disability, 15, 1, 39-53. 